\title{
Del administrado al ciudadano: cuarenta años de evolución *
}

\author{
Francisco López Menudo
}

Catedrático de Derecho Administrativo. Profesor emérito.

Universidad de Sevilla

\begin{abstract}
SUMARIO
I. CONSIDERACIÓN PRELIMINAR. II. LOS RASGOS BÁSICOS DE LAS FIGURAS DEL "CIUDADANO" Y DEL "ADMINISTRADO". LUCES Y SOMBRAS. A). La elasticidad del concepto "ciudadano" y su capacidad de adaptación. B) El "administrado". Una figura lastrada, aunque útil y de dificil sustitución. C) El interesado. D) Conclusión. III. EL ADVENIMIENTO DEL "CIUDADANO" COMO REFERENCIA SUBJETIVA GENTRAL DEL SISTEMA. A) El uso del término y del concepto de ciudadano en nuestra historia constitucional. B) El "ciudadano" en la Constitución vigente. C) El "ciudadano" en la legislación ordinaria. IV. LA FIGURA DEL "ADMINISTRADO” EN EL DERECHO POSITIVO. A) El "administrado" en la legislación preconstitucional. B) El Administrado en la Constitución de 1978. V. "ADMINISTRADO"Y "GIUDADANO" EN LA LEGISLAGIÓN ORDINARIA POSTERIOR A LA CONSTITUGiÓN. VI. EL TRATAMIENTO DE DICHAS FIGURAS EN LOS TRIBUNALES. VII. CONCLUSIÓN.
\end{abstract}

RESUMEN: El cuadragésimo aniversario de la Constitución española de 1978 ha propiciado la aparición de numerosos estudios sobre su impacto en muchísimos aspectos. Los indudables avances del texto constitucional en materia de libertades, derechos fundamentales y, en suma, sobre la posición del individuo en el sistema y frente al poder, se hace patente en el acento que la Constitución pone en la figura del "ciudadano" que se erige así en una idea central que trata de conectar con la noción de Estado de Derecho, como ocurriera en su origen histórico.

Desde este realce, la doctrina suele predicar su fuerte contraste con el concepto de "administrado" tan implantado antes de la Constitución. Pero el presente estudio

* $\quad$ Nota de la R.- Es reproducción literal del trabajo publicado en la magna obra editada por el Centro de Estudios Políticos y Constitucionales, España constitucional (1978-2018) Trayectorias y perspectivas, director Benigno Pendás, cinco tomos, Madrid, 2018. El trabajo aquí transcrito figura en el Tomo V, de dicha obra bajo el parágrafo 238, páginas 3677-3700. La Revista agradece al CEPC su expresa autorización para su publicación en este medio. 
viene a relativizar la fuerza de esa presunta contraposición, subrayando el acierto de que la Constitución misma haya insertado en su texto ambos conceptos.

ABSTRACT: The fortieth anniversary of the 1978 Constitution has led to the emergence of numerous studies on its impact in many respects. The undoubted advances in the constitutional text on freedoms, fundamental rights and, in short, on the position of the individual in the system and in the face of power, is evident in the emphasis that the Constitution places on the figure of the "citizen" that thus stands in a central idea that seeks to connect with the notion of the rule of law, as was the case in its historical origin. With this enhancement, doctrine often preaches its strong contrast to the concept of "managed" so implanted before the Constitution. But this study comes to relativize the strength of this alleged opposition, underlining the success that the Constitution itself has inserted both concepts in its text.

PALABRAS CLAVE:Ciudadano; administrado; interesado; extranjeros; Constituciones, Declaraciones de derechos; participación; democracia representativa.

KEYWORDS: Citizen; managed; interested; foreigners; Constitutions; Declarations of Rights; participation; representative democracy.

\section{GONSIDERACIÓN PRELIMINAR.}

En el contexto de una magna obra como esta cuyo fin es valorar lo que ha significado para España la Constitución de 1978 en los cuarenta años de su existencia, el rótulo del presente ensayo subraya por sí solo, plásticamente, la transformación de uno de los puntos clave a considerar: la posición política y jurídica de las personas. Porque va de suyo que en los términos "administrado" y "ciudadano" hay valores entendidos; el primero lleva adherido, con más o menos razón, el prejuicio del sometimiento del individuo y la opacidad del poder, mientras que el segundo se identifica con la libertad de los sujetos y un poder sometido a controles sin fisuras. Diferencia importante en verdad.

De entrada, conviene dejar sentado con la mayor claridad que la Constitución de 1978 ha alcanzado en este punto cotas realmente encomiables, tanto por el mejoramiento de la situación del individuo que ella misma, per se, ha reportado, como el que ha irradiado hacia todo el sistema, impregnándolo de arriba abajo. Por tanto, hay que celebrar la obtención de una ganancia indiscutible, una aportación esencial que hay que colocar junto a otras igualmente capitales (tutela judicial efectiva, reserva de ley, libertad de empresa, etc). Por consiguiente, bastaría seguir aquí los pasos que ha ido marcando la doctrina sobre la contraposición "administrado-ciudadano" 
para cumplir con el objetivo de enfatizar este logro, ciertamente irrefutable. También en este aspecto concreto la Constitución de 1978 ha prestado un gran servicio.

Dicho lo anterior, cabe ya advertir que la exposición que aquí se hace del tema no sigue el patrón, bien conocido de enfrentar la denostada figura del "administrado" y la del ciudadano como dos realidades extremas e irreconciliables: la primera, representativa de lo negativo, y la segunda de lo bueno e insuperable ${ }^{1}$. Ciertamente, esa dicotomía facilita las cosas, como casi todos los planteamientos maniqueos, que es, con todos los respetos, lo que se ha venido haciendo en este punto. En fin, la opción es la de dar entrada a los matices y no partir del apriorismo de que la figura del "administrado" haya que tenerla ya prejuzgada como condenable; y ello, entre otras razones, porque la Constitución no lo hace, siendo este, por cierto, un mérito suyo que lejos de haber sido bien valorado, como sí lo haremos aquí, la doctrina lo acoge con extrañeza o como "de mala gana". Pero quede claro desde ya: la idea clave no es que el administrado deba sustituir o desplazar al ciudadano, sino que también tiene un espacio propio y no pequeño donde puede jugar útilmente sin que sufran por ello, ni en la forma ni en el fondo, los valores, libertades y derechos que la Constitución, ejemplarmente, ha derramado en nuestro ordenamiento jurídico.

Afirmado lo que precede, es oportuno advertir que no es finalidad de estas líneas profundizar en la regulación del concepto de ciudadano y de sus muchas proyecciones de todo orden, -lo que ha sido ya objeto de excelentes e innumerables estudios $^{2}$ - sino la de resaltar su papel de vector, entre otros, de la transformación operada por la Constitución en los últimos cuarenta años. Además, no parece una vía metodológica adecuada la de polarizar en la figura del ciudadano, anotándolos en su haber, todos los avances y nuevos principios surgidos en los últimos años (rigor en la motivación de los actos, mejoras del procedimiento y de mecanismos tales como el silencio, la superación de la inactividad, etc, etc), de tal modo que tratar de la figura del ciudadano conllevara la carga de exponer tales mejoras como algo inseparablemente suyo, pues si bien hay que admitir que buena parte de esos avances vienen generados

1 En esta contraposición se mueve el trabajo de MONTIEL, F. "El ciudadano y el administrado", en Revista de Administración Pública, núm. 48, 1965, forzando una dicotomía que al menos en la actualidad no puede ser aceptada. Del mismo planteamiento parte el estudio de ELENA CÓRDOBA, A. "De administrado a ciudadano. Veinte años de incidencia de la Constitución en el procedimiento administrativo y en las relaciones ciudadano-administración” en Administración Pública y Constitución, INAP, Madrid, 1998, págs. 559 y ss.; así como la generalidad de los Manuales y trabajos sobre el tema.

2 Así, EMBID IRUJO, A., El ciudadano y la Administración, MAP, Madrid, 1994. PAREJO ALFONSO, L. "El ciudadano y el administrado ante la Administración y su actuación, especialmente la cumplida a través del procedimiento" en Administraciones Públicas y Constitución: reflexiones sobre el XX aniversario de la C.E., edit. INAP, Madrid, 1998, págs. 541 y ss. Y su Derecho Administrativo, edit. Ariel, Barcelona, 2003, págs. 595 y ss. MORENO MOLINA J.A, "Los derechos de los ciudadanos en sus relaciones con la Administración Pública: los interesados en el procedimiento administrativo", EfCLM. núm. 18, 1993, págs. 85 y ss. 
directamente de la mejoría posicional de este sujeto de derecho llamado "ciudadano", en otros muchos casos la mejora del sistema es la inherente a la evolución del conocimiento en general y de la cultura jurídica en particular, sustrato que propicia el florecimiento de principios tales como el de buena administración, confianza legítima, no indefensión, etc. Sin que tampoco pueda olvidarse que el ciudadano no sólo tiene derechos sino también deberes y que no todo el Derecho público se articula para protegerlo y colocarlo en el centro del universo, sino que debe atender igualmente los intereses generales, vertiente ésta que a veces no emerge como debiera en la literatura sobre el tema.

\section{LOS RASGOS BÁSICOS DE LAS FIGURAS DEL "CIUDADANO" Y DEL “ADMINISTRADO”. LUGES Y SOMBRAS.}

Las expresiones mediante las cuales las leyes designan a sus destinatarios podrían formar un catálogo de sorprendente extensión ya que cada ramo o sector de la vida jurídica tiene su elenco específico de actores (donatario, heredero, regante, enfiteuta, contratista, arrendatario, reversionista, expropiado... y un larguísimo etcétera). Aquí sólo cabe considerar las expresiones utilizadas por las normas dirigidas a la generalidad de los sujetos como son las Constituciones y las grandes leyes, en este caso del derecho público. Pues bien, esos textos permiten sentar la conclusión general de que en la historia constitucional el concepto más utilizado es el de español, seguido del de persona; y en el plano de las leyes ordinarias es aplastante la superioridad de la figura del interesado. Pero salvado lo anterior, hay un abanico de expresiones (nadie, ningún, todos, individuos, hombres...) que juegan con intensidad distinta en cada texto, con sus respectivos problemas de delimitación en el aspecto subjetivo. Aquí consideraremos tres de esos conceptos; ciudadano, administrado e interesado; porque hay entre ellos una trabazón consecutiva que aconseja su manejo conjunto.

\section{A). La elasticidad del concepto "ciudadano" y su capacidad de adaptación.}

Como idea primaria o de base hay que distinguir, por el lado subjetivo, un concepto de ciudadano stricto sensu que equivale a "nacional" o "español" (STC 63/1987 de 20 mayo) y que, por tanto, excluye a los extranjeros de cualquier clase $e^{3}$, es decir, los exponentes por antonomasia de la ciudadanía o nacionalidad, cuya adquisición o pérdida se regula por lo dispuesto por el Código civil (arts. 17 y ss.). Por el lado objetivo se identifica con los derechos uti cives del art. $23 \mathrm{CE}^{4}$ referidos a la participación política,

3 Excepto a los extranjeros residentes en España en cuanto al derecho de sufragio en las elecciones municipales (art. 13.2 CE y arts. 8.B) 1 y 19 del Tratado de la Unión Europea).

4 Derecho a elegir a los representantes en todas las instancias territoriales y derecho de sufragio pasivo; derecho a la participación directa (régimen municipal de Concejo abierto, Iniciativa legislativa, 
no a las demás manifestaciones de la participación circunscrita al ámbito administrativo. Además de este núcleo básico o primario, la noción de "ciudadano" comprende también otros derechos de la Constitución, fundamentales o no, y los demás derechos reconocidos por la legislación ordinaria.

Junto a este ciudadano por antonomasia hay que situar la del ciudadano lato sensu que incluye a los nacionales de Estados miembros de la Unión Europea y a los extranjeros de terceros países residentes en España; poseyendo estos un status - derechos, libertades, deberes, obligaciones, cargas- prácticamente igual al de los españoles ${ }^{5}$. Pero no queda aquí el "estiramiento" que el devenir histórico ha operado sobre este concepto pues su generalización en los textos jurídicos y en el lenguaje corriente ha llegado a ser tan extensa e incluso desmesurada que a veces aparece vacío de contenido técnico alguno. Ciertamente, se ha llegado a postular que la denominación "ciudadano" debe ser aplicada a toda persona por el hecho de su mera coexistencia en una sociedad ${ }^{6}$, abstracción hecha de su relación con el Estado o la Administración, concepción ésta sin duda muy sugestiva por igualitaria pero que en la práctica puede no responder a la realidad ni ser operativa para resolver los problemas que pueden plantearse respecto al disfrute de los servicios y demás prestaciones. ¿Cabe afirmar que ha de reconocerse la más absoluta igualdad a todos los seres por el mero hecho físico de que estén pisando un mismo territorio? ¿Es defendible este concepto ilimitado de ciudadano?

Hay, por tanto, una primera acepción del concepto ciudadano dotada de una fuerza histórica y social inconmensurable y una segunda que hace del concepto algo anodino y, a la postre, trivial e incluso desfasado y chocante en algunos casos. Esta inflación del concepto ha corrido paralela al desarrollo formidable de la Constitución y de todo el movimiento asociativo surgido al abrigo del régimen de libertades con el consiguiente acercamiento de las personas a las estructuras administrativas ${ }^{7}$, hasta tal punto de que tal concepto llega a traspasar las fronteras de lo público hasta hacerse un hueco también en el lenguaje del ámbito privado, donde puede llegar a ser desde útil hasta ridículo.

Es ocioso decir que este uso generalista de la expresión "ciudadano" nada tiene que ver con el perfil de la figura surgida de la Revolución de 1789, circunscrita a las libertades y derechos esenciales y plagada de limitaciones. Además, no deja de

Consultas populares); acceso al desempeño de cargos públicos o que impliquen ejercicio de autoridad.

5 "en los términos que establezcan los tratados y la ley" (art. 13.1 CE), entre los que destacan los que corresponden exclusivamente a los españoles (ex art. $23 \mathrm{CE}$; o por ejemplo, "defender a España”, art. 3)

$6 \quad$ En la línea indicada, la STS 21 febrero 2011, Sala $5^{\mathrm{a}}$.

7 MUÑOZ MACHADO, S., Vid. Tratado de Derecho Administrativo y Derecho Público General, Edit. IUSTEL, IV, pág. 520. Son muy ilustrativos los datos que el autor muestra respecto al crecimiento del "tercer sector" a partir de 1977. 
admirar la subsistencia histórica del concepto pues no todo en él tiene una connotación "venerable". Baste considerar, por ejemplo, que de este status estaban excluidas las mujeres ${ }^{8}$, cuyo derecho a voto en España se demoró hasta 1931; así como otras máculas que muestra la Historia, como la exclusión de ciertas personas (esclavos, empleados domésticos, sirvientes) y las restricciones inherentes al voto censitario. Por añadidura, se trata de un concepto difuso que plantea dudas sobre si comprende o no a las personas jurídicas, las entidades de hecho o los menores de edad ${ }^{9}$.

La Constitución vigente aborda el tema de frente y por derecho y utiliza resueltamente el vocablo ciudadano con plena legitimidad pues de la propia Constitución resulta meridianamente claro que dicha expresión queda limpia de adherencias históricas negativas, carece de connotación rechazable alguna y se asienta en la fórmula del "Estado social y democrático de Derecho" (art 1 CE), un modelo que hace cuarenta años, cuando la Constitución apareció, estaba ya consolidado y bien comprendido por la ciencia política. Por ello esta nueva figura de ciudadano aparece recargada de sentido, con la incorporación de valores que no se encontraban en su origen.

Valorando esta circunstancia, algunos propugnan que su uso es válido para toda situación en la que se encuentre un sujeto, o sea, una persona ${ }^{10}$; insistiendo en que la figura del ciudadano, pese a sus quiebras, es la correcta en todo caso y, en cierto modo, más expresiva del pleno status jurídico de las personas que se relacionan con la Administración pública ${ }^{11}$. Otros autores, en cambio, no dejan de advertir la impropiedad de su utilización en algunos casos y los problemas que luego se plantean en la práctica a la hora de delimitar los sujetos afectados por la norma ${ }^{12}$.

8 Es oportuno mencionar al respecto la temprana reacción de la sufragista francesa Oliympe de Gouges con su "Declaración de los Derechos de la Mujer y de la Ciudadana" de 1791, en plena Revolución.

$9 \quad$ Estos en cuanto excluidos al menos de los derechos políticos primarios de la ciudadanía ex art. 23 CE. Por otra parte, no está en los usos llamar "ciudadano" a un niño o niña. Puede decirse también que extender la condición de "ciudadano" a las personas jurídicas u otras entidades fuerza demasiado el concepto, hasta romperlo.

10 SAncheZ MORON, M., Derecho Administrativo, Parte General, $11^{\text {a }}$ edic., Edit. Tecnos, Madrid, 2015, pág. 448.

11 Así COSGUlLUELA, L. De hecho, su Manual estructura su Titulo Sexto sobre la figura del ciudadano, evitando la palabra administrado.

12 Así lo advierte con tino VERA JURADO, D. en Derecho Administrativo, Tomo I (dirig. Rebollo Puig-Vera Jurado) $2^{\circ}$ edic., pág. 192. Es muy cierto lo que afirma y prueba de ello es el problema que resuelve la STS de 21 febrero 2011, Sala 5 . Por otro lado, también se viene a decir que los "derechos del hombre y del ciudadano" es terminología de 1789 producto de "la borrachera que produjo la sustitución del status de súbdito (sujet) por el status de ciudadano (citoyen)" y que debe ser superada, siendo más oportuno hablar de Derechos humanos; así, GONZÁLEZ NAVARRO, F., Derecho Administrativo Español**, 2a edic., EUNSA, 1994, pág. 133. 
Es muy plausible el advenimiento del concepto ciudadano y un uso decidido del mismo; pero puede no ser sensata su utilización a ultranza sólo por exhibir una pose de modernidad o progresismo. Concretamente, hay situaciones en que hablar de "ciudadano" y no de "administrado" o "interesado" supone desperdiciar la ventaja que ofrecen conceptos acrisolados por las leyes y en el lenguaje jurídico sin ventaja o contrapartida de ninguna clase, salvo, quizás, la de mostrar una pose ideológica reticente que a estas alturas está fuera de lugar. En conclusión, puede sostenerse que existe un concepto jurídico de ciudadano que conviene mantener en sus justos límites; un concepto político en el que juega como sinónimo de persona y que funciona por lo general en infinidad de supuestos relacionados con la cosa pública; y un concepto social en el que circula en todos los ámbitos, sin orden ni concierto.

\section{B) El "administrado". Una figura lastrada, aunque útily de difícil sustitución.}

Administrado es la persona, física o jurídica, nacional o extranjera, susceptible de entablar relaciones con las Administraciones Públicas (ENTRENA GUESTA); es esta una definición sencilla que puede considerarse perfecta tanto por lo que se refiere a las personas comprendidas ${ }^{13}$ como porque apunta a las Administraciones Públicas como contraparte -y no genéricamente a los Poderes públicos, como es lo propio del ciudadano- y, además, habla de la susceptibilidad de entablar relaciones -sujetas al Derecho Administrativo ha de entenderse-, sin necesidad de que estas estén establecidas. O sea, la definición apunta a una posición que puede materializarse o no en una relación jurídica concreta que es cuando el administrado se convierte en un "interesado". Por tanto, todos los ciudadanos son administrados si el posicionamiento de sus derechos y deberes es frente a la Administración, como ocurre por lo general. O sea, que en cuanto se establezca un punto de conexión con la Administración surgirá el "administrado"; y ha de tenerse en cuenta que la Administración es dentro del Estado quien prácticamente monopoliza las relaciones jurídicas con los particulares. Por esta razón el concepto de administrado abarca no sólo a los ciudadanos, sino a cualquier persona extranjera que se halle ante la Administración, incluidos los llamados "sin papeles". Resulta evidente la flexibilidad del concepto y su gran utilidad.

No es tarea fácil localizar en la Historia el surgimiento del "administrado". Este concepto no tiene la connotación "gloriosa" que sí tiene el de ciudadano sino un cierto perfil de intruso aparecido en el mundo del Derecho público de forma soterra-

13 Faltaría incluir a los entes o grupos sin personalidad a los que la Ley 11/2007 de 22 de junio de acceso electrónico extendía incluso la condición de ciudadanos. En cuanto a si cabe considerar como administrados a las personas jurídicas de Derecho Público parece que la respuesta debe ser afirmativa en cuanto haya superioridad en la otra parte, no en otro caso, como afirmara en su día GARCÍA TREVIJANO, J.A., Tratado de Derecho Administrativo, Tomo I, $2^{\mathrm{a}}$ edic., Edit. Revista de Derecho Privado, Madrid, 1968, pág. 503. 
da y en fechas desconocidas ${ }^{14}$. La doctrina no ha establecido nunca cuándo ni cómo naciera tal concepto, aludiéndose vagamente a un tiempo pretérito difuso que unos colocan en etapa inmediatamente anterior a la Constitución de 1978, otros en épocas más lejanas y algunos, en fin, en un remoto pasado ligado al Ancien Régime con el que llegaría a confundirse y ser equivalente al de "súbdito" que, por cierto, es el socorrido símil al que acuden para descalificar la figura muchos de los autores detractores del uso de la noción de "administrado".

Un atento examen de la literatura jurídica del pasado permite sentar la conclusión de que el surgimiento y desarrollo de la expresión "administrado" corre paralelo al de la propia Administración contemporánea. Por tanto, queda aquí descartada la tesis de que tuviera algo que ver, cronológicamente hablando, con el Antiguo Régimen ni que haya sido equiparable en ningún momento histórico a la figura del súbdito. Más bien hay que afirmar que en la idea de "administrado" ha pesado más negativamente su nombre que su sustancia. Esta sustancia ha sido la que ha deparado el sistema jurídico de cada momento histórico, al igual que ha ocurrido con el concepto de ciudadano o cualquier otra figura o institución.

Es importante subrayar de entrada el magistral enfoque del profesor GARCÍA DE ENTERRIA, al sostener, en frase celebérrima, que "este término de administrado es, realmente, poco feliz" porque "parece argüir una posición simplemente pasiva de un sujeto". Frases a la que añadía seguidamente, con todo acierto, que "esta connotación pasiva que el nombre de administrado evoca inevitablemente es inexacta hoy, tanto política como jurídicamente". Hay que notar que tal afirmación data de 1977, es anterior a la Constitución.

Pues bien, la reflexión inicial -"poco feliz"- es la que, como un eslogan, ha corrido como la pólvora por los manuales al uso en los que se repite como una cantinela no tanto el infortunio del nomen de la figura -que es lo que el profesor ENTERRIA señaló con elegante precisión-, sino la figura misma como desgracia en sí, lo cual tergiversa la tesis del autor.

En efecto, se ha dicho hasta la saciedad que este término no es el más apropiado en un Estado democrático de Derecho bien por esa su semejanza con la figura del súbdito, bien porque evoca una Administración irresistible como potentior persona. Por ello, la crítica ha alcanzado al propio artículo $149.1 .18^{\text {a }} \mathrm{CE}$ y demás leyes que han seguido utilizándolo. Y como refuerzo de tal postura la doctrina acude incluso al Diccionario de la RAE cuya definición de "administrado" ("Persona sometida a la

14 GONZALEZ NAVARRO, F. se ha referido al administrado como "un oscuro personaje frecuentemente olvidado", El procedimiento administrativo español en la doctrina científica, Presidencia del Gobierno, Secretaría General Técnica, BOE, Madrid, 1972, pág. 265 
jurisdicción de una autoridad administrativa" ${ }^{15}$ - que data de 1780, o sea, $1^{\text {a }}$ edición- anacrónica y jurídicamente inexacta en cuanto anterior a la propia Revolución Francesa, contribuye a echarle aún más tierra encima a una figura con nombre ciertamente desdichado.

No debe ser pasado por alto el hecho de cómo los autores, incluso los más reacios al uso de la expresión "administrado", luego de haberlo condenado suelen reconocer que éste detenta igualmente posiciones activas y además suelen ocuparse de la importante distinción entre la situación de sujeción general y de la especial, hablando ya sin remilgos de la correlativa distinción entre administrados simples y cualificados, adjetivos que sin duda empeoran la voz "administrado" a secas, visto esto desde la perspectiva de ese "lenguaje socialmente correcto" tan adictivo. En efecto, nunca se habla de "ciudadano simple" o de "ciudadano en una relación especial de sujeción".

Cabe reiterar lo dicho. A la vista de la doctrina clásica no hay razones para demonizar al "administrado" por su supuesta ligazón con la imagen del súbdito. Así, en mitad del siglo XIX, las obras de ORTIZ DE ZÚÑIGA, GÓMEZ DE LA SERNA o COS GAYON ignoran el término "administrado" y señalan al "ciudadano" con toda naturalidad como sujeto poseedor de los derechos políticos, incluso cuando la figura era eludida por las Constituciones a la sazón en vigor, si bien la invocación predominante la hacen al individuo o a la persona.

Algunos años después, COLMEIRO hace emerger la figura del administrado, aunque de modo menos marcado que el de persona, que es el concepto ordenador de su obra, la de español; y es importante resaltar el dato de que a finales del XIX y principios del XX la figura del administrado es inexistente en obras tan influyentes como las de SANTAMARIA DE PAREDES.

Un sector minoritario (GARGIA OVIEDO, GARGIA TREVIJANO, GONZÁLEZ PÉREZ, ENTRENA GUESTA, ESCUIN PALOP) acoge la figura del administrado sin prejuicios y lo que propugna es que se profundice en orden a conseguir equilibrios entre el poder y los privados, mediante, por ej., la formación de un

15 Esta definición se ha mantenido largamente en el tiempo. La edición núm. 23 del DRAE (2014) la ha sustituido por "Dicho de un ciudadano: Sujeto a las Administraciones públicas", que tampoco es jurídicamente acertada, puesto que no hay equivalencia plena entre administrado y ciudadano. La nota de la sujeción -que no de la sumisión- sí es correcta.

Buscar apoyos en los Diccionarios para sustentar la tesis de que "administrado" significa sumisión es realmente estéril, y lo cierto es que se han hecho muchas elucubraciones en este sentido. No todo participio pasivo sugiere inferioridad (por ej. en el binomio demandante-demandado). Baste decir que a diferencia de lo que ocurre con la palabra gobernado frente a gobernador, la voz "administrado" también puede significar superioridad, si "administrar" se toma como "servir" o "suministrar", acepciones éstas que algunos Diccionarios y Enciclopedias -Larousse- admiten. Así lo resaltaba SANTAMARÍA DE PAREDES, V. al decir que se llama "administrador al que administra en nombre de otro... aplica medios a fines, ejecuta lo que le está ordenado, sirve a quien representa". Curso de Derecho Administrativo, $7^{\mathrm{a}}$ edic. Madrid, 1911, pág. 36. 
estatuto del administrado (GONZÁLEZ PÉREZ16) o la reunión en una tabla de los derechos que las leyes establecen de modo disperso (GARCIA OVIEDO ${ }^{17}$ ). En fin, contundente en esta línea es la opinión de ESCUIN para quien el administrado es precisamente una consecuencia del Estado de Derecho: el que desplaza la figura del súbdito y puede en ocasiones actuar exclusivamente como titular de posiciones activas, correspondiendo a la Administración la totalidad de las pasivas ${ }^{18}$.

En suma, lo que se desprende de cuanto queda expuesto es que la idea de "administrado", tan claudicante por su "tara" gramatical de ser el participio pasivo de un verbo -administrar- que simboliza el Poder, ha servido a los autores como fácil chivo expiatorio para marcar distancias con el régimen político preconstitucional.

La llegada de la Constitución de 1978 hacía presagiar que el administrado desaparecería del lenguaje jurídico, máxime cuando la LRJAP y PAC de 1992, al predicar del ciudadano y no del administrado los derechos relacionados en su artículo 35 ("Derechos de los ciudadanos") pareció finiquitar esta última figura. Pero el término administrado sigue vivo aun cuarenta años después de la Constitución. Con toda rotundidad puede afirmarse, por tanto, que la Constitución ha contribuido a reforzar las garantías del administrado en múltiples aspectos (por ej. relajando las exigencias de legitimación, estableciendo reserva de ley para regular aspectos ligados a la figura, etc), no para suprimir ni descalificar la figura. Es ejemplificativa la STC 195/1992 de 16 novbre.

\section{C) El interesado.}

Se trata del administrado que por estar legitimado entabla una relación concreta con la Administración Pública en un procedimiento ${ }^{19}$. Como señalara VILLAR PALASI, es el concepto fundamental para el Derecho Administrativo. Y es la verdad según quedó sentado supra.

\footnotetext{
16 El Administrado, Publicaciones Abella, Madrid, 1966, pág. 24. Este acoge incluso con simpatía la figura del administrado, lamentando que la doctrina se haya ocupado casi exclusivamente de la Administración y sus prerrogativas; idem, págs. 8 y 9.

17 GARCÍA OVIEDO-MARTÍNEZ USEROS, Derecho Administrativo I, $9^{\text {a }}$ edic. EISA, 1968, pág. 170. Es curioso contrastar su vehemente deseo de que el legislador de la época se decidiera a redactar una tabla de derechos del administrado, con la proliferación de Declaraciones, tablas y demás relaciones de derechos como fenómeno de los tiempos actuales cuya inflación provoca precisamente una cierta desvalorización de su contenido. No le faltaba razón al citado, pues no pocos autores actuales ven en la mera existencia de una tabla de derechos el signo evidente de la ciudadanía, una visión formalista de las cosas no exenta de ingenuidad.

18 ESCUIN PALOP, V., Elementos de Derecho Público, 8ª edic. Edit. Tecnos, Madrid, 2014, pág. 162.

19 Su definición legal es la contenida en el artículo 4 de la Ley 39/2015 de 1 de octubre del PAC.
} 


\section{D) Conclusión}

Expuesto lo que antecede debe quedar claro que los ciudadanos se posicionan de hecho como administrados, y operan en la práctica como interesados, pues tales conceptos no son incompatibles. Pero necesitando el Derecho, como cualquier otro arte o ciencia, de una especialización del léxico capaz de precisar las ideas, deben escogerse y utilizarse preferentemente los términos más exactos o aquilatados posibles frente a los más genéricos o difusos. Por ejemplo, es evidente que el derecho a aportar pruebas o presentar alegaciones conecta tan íntimamente con la idea de "interesado" que el uso de la voz ciudadano en estos casos, aunque no ilegal, puede ser impropia e incluso chocante.

En consecuencia, la línea aquí defendida es la de no desmesurar la idea del "ciudadano", dado el riesgo que supone para el concepto mismo una utilización no técnica del vocablo ${ }^{20}$. Aproximativamente podría decirse que en el plano jurídico debe ser un término reservado para las grandes declaraciones; o para los asuntos en que lo importante a realzar sea la persona y sus valores cívicos; y para cuando haya que referirse al status de ciudadanía en sentido estricto - participación en los asuntos públicos, art. $23 \mathrm{CE}$ - o derechos ciertos reconocidos por las leyes, porque aquí es donde muestra a plenitud todo su peso histórico y todo un mundo de valores entendidos; o cuando conecte a la población en general con asuntos relativos a la res pública sin constituir por ello relaciones jurídicas. Pero importa mucho subrayar que a su lado debe operar, compatiblemente, el concepto de administrado dado su amplísimo espectro al comprender todas las situaciones imaginables de cualquier sujeto frente al Poder, salvo aquellas contadísimas en que no interviene una Administración u órgano asimilado.

\section{EL ADVENIMIENTO DEL "GIUDADANO" COMO REFEREN- CIA SUBJETIVA GENTRAL DEL SISTEMA.}

\section{El uso del término y del concepto de ciudadano en nuestra historia constitucional.}

El concepto de ciudadano es esencialmente evolutivo y cambiante en la historia y en la filosofía. Dicho sea en pocas palabras: la voz "ciudadano" tanto ha servido

20 La propia Constitución no depura el lenguaje cuando en el artículo 105, letras a) y b) habla de los "ciudadanos" refiriéndose al derecho de audiencia en el procedimiento administrativo; o el acceso a los archivos y registros administrativos. Desde luego no es que ello sea incorrecto pero el término más preciso que hubiera cuadrado a ambos supuestos es el de administrado. Desde otro punto de vista PAREJO ALFONSO, L., ve en dichos apartados del artículo 105 la polivalencia del concepto de ciudadano, o sea que "el status de los sujetos ordinarios del Derecho en su relación con la Administración no es único, experimentando modulaciones en función de los términos y circunstancias en que se produce la trabazón de dicha relación" "El ciudadano y el administrado...", ob. cit. 
de bandera de los ideales progresistas como ha sido muchas veces arrumbada por retrógrada y caduca. Es imprescindible tener esto muy en cuenta para interpretar correctamente nuestros textos constitucionales del pasado. Indudablemente, las palabras que usan esos textos suelen proporcionar las pistas para descubrir la ideología que subyace en cada uno de ellos, pero a veces no se da esa correspondencia por encontrarse el lenguaje mediatizado por condicionantes económicos y sobre todo sociales que son decisivos al respecto; en este sentido opera el llamado "lenguaje político correcto"; o sea, el que logra asentarse en los usos y en la legislación aun careciendo a veces de rigor técnico alguno, jurídico o filológico.

Sentado lo anterior, puestos ya a valorar como es debido el gran mérito de la Constitución de 1978 de compendiar en la noción de ciudadano todas las virtudes que confluyen en la fórmula del Estado Social de Derecho, es conveniente hacer, siquiera sea brevemente, un seguimiento histórico del concepto pues sólo de tal modo puede ser captada la enorme relevancia de la Constitución en este tema, que es de lo que se trata.

Y para ello, no hay punto de arranque más seguro que el que ofrecen las Declaraciones de derechos de finales del siglo XVIII, señaladamente la Declaración de los Derechos del Hombre y del Ciudadano de 26 de agosto de 1789, aunque este honor sea disputado por la coetánea Constitución de Virginia de 1774 e incluso por el Bill of Rights de 13 de febrero de 1689, resultante de la Revolución inglesa del año precedente. Cierto es que la historia de siglos anteriores al XVIII ofrece nutrido muestrario de declaraciones, cartas, reconocimientos, etc. pero, como advierte GARGIA PELA$\mathrm{YO}^{21}$ tales proclamaciones de derechos no eran generales ni tenían por destinatarios a los individuos considerados como tales -imposible era entonces concebir una tensión dialéctica entre el Monarca y sus súbditos- sino que estaban promovidas o eran dirigidas a determinados estamentos, clases, gremios, etc, en cuyo marco la expresión "ciudadano" no tenía cabida.

Por ello el vocablo despliega todo su sentido político justamente en las primeras Declaraciones de derechos individuales, siendo paradigmático el caso de la de 1789 ("del Hombre y del Ciudadano"), un hecho histórico trascendental que puede sintetizarse en el principio de igualdad de todos los ciudadanos ante la Ley y el reconocimiento de la libertad civil frente al Estado. La difusión de este principio tuvo prolijo desarrollo en las Constituciones francesas posteriores a la de 1789, así como notable expansión en otros Estados europeos continentales. Por citar un ejemplo paradigmático de este impacto es de resaltar la Constitución francesa de 1791, inmediata posterior a la Declaración, en la que luce a primera vista el uso de la expresión "hombre", quedando

21 Derecho Constitucional Comparado, edic. Manuales de la Revista de Occidente, Madrid, 1950, pág. 125. Asimismo, MUÑOZ MACHADO, S., Tratado de Derecho Administrativo... cit., I, pág. 444. 
realzada la de "ciudadano" de modo reluciente. Como es lógico, tales textos también se dirigen con profusión a los "franceses" o al "pueblo" pero en una acepción subjetiva que no se aparta de la línea que en tal momento histórico se quería destacar, esto es, el derecho de los individuos. Valga decir como conclusión que, como puede suponerse, no existe en tales textos mención alguna al "administrado", pese a que en esta época ya se dan los presupuestos necesarios para que tal vocablo pudiera haber surgido.

Las palabras de una Constitución no son nunca inocentes, tienen un valor indicativo de primer orden. Pero no hay que estar sólo a las palabras sino al contenido, y en el caso del vocablo "ciudadano" su valor real depende de los derechos reconocidos y la fiabilidad de estos. El banco de pruebas por excelencia para detectar si se da o no esa correspondencia es el derecho de sufragio en cuanto máximo exponente de un verdadero status de ciudadanía. En este sentido debe marcarse una clara línea divisoria entre las Constituciones que reconocen e incluso realzan este derecho y las que sencillamente lo ignoran o hacen genérica alusión a las leyes para que éstas lo reconozcan y regulen ${ }^{22}$.

a) La primera apreciación de relieve que puede hacerse sobre la expresión "ciudadano" en las Constituciones españolas, es la de su muy escaso uso, en contra de lo que podría en principio suponerse. Ya sorprende la nula mención de este vocablo en el Estatuto de Bayona (1808) lo que supuso la primera claudicación del concepto tras su eclosión, tan próxima en el tiempo ${ }^{23}$. Por el contrario, hay un verdadero derroche en la utilización de este término en la Constitución de 1812. En esta se encuentra el apogeo de la figura y la máxima correspondencia entre el vocablo y los principios originarios del Estado de Derecho ${ }^{24}$. La Constitución gaditana universaliza el concepto de ciudadano (de la ciudad a la nación) y lo extiende a lo rural (de la ciudad al ámbito rústico), ampliando considerablemente el cuerpo de ciudadanos al transformar las colonias españolas en provincias y otorgar el status de ciudadanía a los antiguos súbditos del Estado absoluto. Así, su lacónico e impresionante artículo $1^{\circ}$ ("La Nación española es

22 De una parte, por ejemplo, la de Cádiz, que incluso lo regula prolijamente; la Constitución de 1869 (art. 66: "Para ser diputado se requiere ser español, mayor de edady gozar de todos los derechos civiles") y con fórmula semejante el Proyecto de Constitución Federal de 1873 (art. 18). Guardan en cambio absoluto silencio el Estatuto Real de 1834 y la Constitución de 1876. La de 1845 proclama abiertamente su sistema, que era acusadamente censitario. La de 1837 remite simplemente a la ley electoral que, como más abajo se dirá, fue notoriamente restrictiva.

23 El Estatuto de Bayona, en consonancia con los principios de la Revolución pone el énfasis en el individuo y la persona, e incluso formula su propia tabla de Derechos y libertades (arts. 124 y ss).

24 Dada la considerable extensión de la Constitución gaditana su texto pudo dar cabida a toda una galería de términos diversos con los que señalar a los destinarios de sus preceptos ("individuo", "persona", "español"...), es decir, conceptos más o menos equivalentes o sinónimos, pero destacando sobre todos ellos el de "ciudadano". 
la reunión de los españoles de ambos hemisferios") y su artículo $18^{25}$. La Constitución doceañista no contiene propiamente una tabla de derechos, pero el reconocimiento de los nuevos derechos esenciales (igualdad, inviolabilidad de domicilio, derecho de educación, abolición de la tortura...) figuran salpicados a lo largo de su texto. En lo negativo, no reconoce ningún derecho a la mujer, ni siquiera la condición de ciudadana pues el derecho de sufragio estaba limitado a los varones mayores de 25 años. Tras la Constitución gaditana se produce la súbita desaparición del concepto "ciudadano" en las Constituciones posteriores, hasta llegar a la vigente de 1978 en la que el concepto resurge con fuerza ${ }^{26}$.

En efecto, un giro radicalmente opuesto ofrece el Estatuto Real de 1834 pues la omisión del "ciudadano" en su texto es absoluta". Y lo mismo ocurre con la Constitución de 1837 nacida al calor del consenso entre progresistas y moderados, no extrañando, a la vista de su corte, que la mención a los "ciudadanos" sea inexistente ${ }^{28}$. La Constitución de 1845, redactada bajo el Gobierno de Narváez, está en línea de continuidad con la Constitución anterior, especialmente por lo que atañe al reconocimiento de derechos individuales y a la posición del "ciudadano" en el sistema, del cual no se hace la mínima mención.

Poco cabe decir aquí sobre la Constitución de $1856^{29}$ dada su condición de non nata, pero sí de su influencia sobre la Constitución de $1869^{30}$. Llama la atención que,

25 Dice este que "son ciudadanos aquellos españoles que por ambas líneas traen su origen de los dominios españoles de ambos hemisferios y están avecindados en cualquier pueblo de los mismos dominios".

26 Ello, con la sola excepción del Proyecto de Constitución Federal de 1873, pero que quedó sólo en eso, un Proyecto.

27 El Estatuto de 1834 está huérfano de menciones a los derechos individuales lo que en puridad era consecuente con el hecho de que se trata más bien una Carta otorgada por la Regente María Cristina de Borbón cuya finalidad fue precisamente la de alejarse del liberalismo representado por la Constitución gaditana.

28 En la Constitución de 1837 la condición de ciudadano quedó extraordinaria mermada por la ley electoral al establecer ésta un sufragio censitario tan restrictivo que venía a excluir del censo al 95 por ciento de los españoles. No contiene una tabla de derechos en forma de Declaración, aunque al referirse al status de los españoles desgrana una serie de derechos, algunos escasamente garantizados (libertad de prensa sin previa censura, derecho de petición, acceso a empleos y cargos públicos, prohibición de confiscación de bienes, principio de irretroactividad penal).

29 Como es bien sabido, el texto estaba fuertemente imbuido de ideología liberal, nutrido de las ideas del "bienio progresista" al que dio fin la rebelión del general O’Donnell, generando así el "aborto", en el más real sentido de la palabra, de esta cuasi Constitución. No pocas de sus ideas fueron recogidas luego en la Constitución de 1869.

30 La Constitución fue dictada tras la Revolución del año anterior y la caída de Isabel II. Fue elaborada democráticamente, sobre el telón de fondo de unas Cortes constituidas por un cuerpo electoral de unos cuatro millones de individuos varones mayores de 25 años (número de electores que supuso un gran avance en aquella época). Su Título I ("De los españoles y sus derechos") constituye una auténtica tabla de derechos, incomparablemente más completa que las Constituciones precedentes pero con la particularidad 
pese al marcado acento liberal progresista de ésta, su texto no haga mención a la figura del "ciudadano", destacando en cambio sobremanera el uso casi exclusivo de la palabra "español" titución Federal de 1873, renace y con mucha fuerza la expresión "ciudadano" -aunque no con el fortísimo protagonismo que tal vocablo tuvo en la Constitución de Cádiz o tiene en la vigente de 1978- y ello aun siendo este Proyecto un trasunto de dicha Constitución de $1869^{32}$, o sea, profundamente liberal en materia de libertades y derechos. Por tanto, el Proyecto logra recuperar lo que sería el "lenguaje político correcto" para una ideología como la imperante en tal momento histórico.

Tres años después aparece la Constitución canovista de 1876, que lejos de asumir el término ciudadano tan recientemente "refrescado" por dicho Proyecto, lo desecha absolutamente ${ }^{33}$.

En principio puede sorprender el uso discretísimo que de la expresión "ciudadano" hizo la Constitución de 1931, pese a los valores democráticos que proclamaba ${ }^{34}$, lo que puede encontrar explicación en la influencia que tuvo sobre ella la Constitución de Weimar de $1919^{35}$ prácticamente huérfana de dicho término, quizás porque a esas alturas del siglo XX el devenir político buscaba distanciarse del concepto "ciudadano", tan asociado desde su origen a la ideología liberal. Pero, al margen del lenguaje, la Constitución de la II República hizo aportaciones decisivas para la configuración misma del concepto de ciudadanía marcando un antes y un después en la historia de la democracia al reconocer el derecho electoral activo y pasivo de

añadida de que, en relación con ciertos derechos, la Constitución misma los garantizaba expresamente (art. 31).

31 Ello amén de las clásicas fórmulas de tipo genérico como el "nadie", "ninguno", "individuo" o persona", lo que viene a demostrar lo que más arriba quedó apuntado, esto es, la falta de concordancia que a veces se produce entre la ideología imperante y el lenguaje utilizado.

32 La declaración de derechos del Proyecto de 1873 fue tomada de la Constitución de 1869. En efecto, su Título II, rotulado de la misma forma ("De los españoles y sus derechos"), reproduce casi en su totalidad el Título correlativo de esta, con algunas llamativas diferencias: la libertad de cultos (art. 34), la separación entre la Iglesia y el Estado (art. 35) y la abolición de los títulos de nobleza (art. 38).

33 No es casual en este caso que emerjan con enorme fuerza las alusiones al "español", superando en esto incluso a la Constitución de Cádiz. Esta divergencia con el Proyecto de 1873 no es meramente lingüística sino que se explica por razones de fondo. Las diferencias sustantivas entre una y otra Constitución son bien elocuentes; baste compararlas en lo que concierne al derecho de sufragio (art. 42 del Proyecto).

34 La Constitución republicana de 1931, profundiza en el reconocimiento de los derechos individuales y colectivos y -aquí su aportación sustancial- establece garantías jurídicas para su efectividad, entre ellas el recurso de amparo. Es su importante Título III ("Derechos y deberes de los españoles") el que contiene estos derechos y garantías.

35 Así fue expresamente reconocido por Adolfo POSADA, miembro de la Comisión Jurídica redactora del Proyecto, en el acto de su presentación. 
las mujeres en igualdad al de los hombres ${ }^{36}$; por tanto, por primera vez transforma el vocablo "ciudadano", antes radicalmente masculino, en un término ambivalente, o sea, apto para comprender a los dos sexos.

Para el fin aquí pretendido son de citar las llamadas Leyes Fundamentales del Reino $^{37}$ que cubrieron la larga etapa franquista. Como rasgos muy caracterizadores y de notable interés pueden establecerse los tres siguientes: a) aparece una expresión nunca utilizada por las Constituciones (salvo la francesa de 1791) cual es la palabra "hombres" como equivalente a personas, voz que monopoliza prácticamente el modo de designar a los sujetos; b) en ningún caso es mencionada la palabra "ciudadano" pese a que tales Leyes nacieron en distintos momentos y muy distanciadas entre sí (treinta años entre la primera y la última); c) un dato muy significativo: tampoco aparece en ellas el término "administrado", lo que será valorado aquí mismo, seguidamente.

b) Otra apreciación general de mucho interés es que la voz típica con la que las Constituciones designan a los titulares de derechos y deberes es la de "español", y ello de manera constante y en abundancia, desde el Estatuto de Bayona hasta la Constitución de 1978.

c) Por último, la tercera gran aseveración que cabe hacer es que ninguna Constitución española -o extranjera de nuestro entorno- hace la menor alusión a la figura del "administrado", con una sola excepción: la Constitución vigente de 1978, singularidad de la que se tratará seguidamente.

\section{B) El ciudadano en la Constitución vigente.}

La Constitución de 1978, segunda en extensión tras la de Cádiz, utiliza al igual que esta una nomenclatura variada para designar a los sujetos. Destaca, sobre todas, la palabra "español", como equivalente a la de ciudadano stricto sensu, como se deduce claramente del contraste entre los artículos 13 y 23. Así resulta claramente también de la tabla de los "Derechos y deberes de los ciudadanos", el primero de cuyos artículos prueba elocuentemente esta equivalencia: "Los españoles tienen el derecho y el deber de defender a España", art. 30. También es profusa la voz persona, genéricamente alusiva a los seres físicos o jurídicos, en la mayoría de los casos sin intención delimitadora en lo

36 Reconocimiento este lleno de vicisitudes y preñado de reticencias y recelos - el miedo a la irrupción por esta vía del voto ultraconservador apegado a la Iglesia- de las que da cuenta Santos JULIÁ en La Constitución de 1931, edit. Iustel, Madrid. Tal reconocimiento terminó fraguando en el justamente famoso artículo 36: "Los ciudadanos de uno y de otro sexo, mayores de veintitrés años, tendrán los mismos derechos electorales conforme determinen las leyes".

37 Decreto 779/1967, de 20 de abril, por el que se aprueban los textos refundidos de las Leyes Fundamentales del Reino. 
subjetivo $^{38}$. También el todos o el nadie son objeto de un uso muy destacado, superando en esto a cualquier Constitución precedente.

En cuanto al uso del término y del concepto ciudadano, la Constitución no es tributaria de las grandes Declaraciones de Derechos del siglo XX anteriores a ella ${ }^{39}$ puesto que estas Declaraciones no se refieren a los ciudadanos o sujetos políticos sino a las personas, lo que tiene todo sentido y, más aún si cabe, en un texto posterior a la Constitución cual es la Convención sobre los Derechos de las personas con discapacidad de 2006. Sí es lógico que la Carta de los Derechos Fundamentales de la Unión Europea de 7 diciembre de 2000, contenga preceptos relativos a la "Ciudadanía" de la Unión (arts. 39 y 40$)$.

En cambio, sí han tenido influencia en este punto las Constituciones que en gran medida inspiraron al constituyente español, todas las cuales hacen un uso generoso de la expresión ciudadano; así la de Italia de 1947 (incrementado dicho uso con la reforma de 2007), Grecia de 1975, y sobre todo Portugal de 1976 en la que dicho vocablo tiene una presencia superlativa.

Como curioso contrapunto sorprende a primera vista el caso de la Ley Fundamental de Bonn, 1949, en cuyo articulado asoma la expresión "ciudadano" sólo en un par de ocasiones. Pero si se tiene en cuenta que siendo la Ley Fundamental la punta de lanza que abre el camino a la fórmula del Estado Social, la voz "ciudadano" pudo estimarse en aquel momento como inadecuada, dadas sus conexiones con el Estado de Derecho, a secas, tan desgastado por aquel entonces y de tan trágica memoria.

Claramente se ve que tanto el vocablo ciudadano como su concepto, es una pieza motriz del mecanismo constitucional. En efecto, figura en preceptos muy principales, tales como el artículo 9 y algunos otros de la Sección 1 ${ }^{a}$, Cap. II, Titulo I, (rotulada Derechos fundamentales y Libertades públicas), de entre ellos el art. 23 sobre el derecho a participar en los asuntos públicos y a acceder a las funciones y cargos. En la Sección $2^{\text {a }}$ (arts. 30 a 38), dedicada a los Derechos y deberes, éstos se predican precisamente de los "ciudadanos"; y con igual o mayor razón las libertades y derechos fundamentales proclamadas en la Sección $1^{\text {a }}$ (art. 531y 2). El apartado 3 del mismo art. 53 no hace la misma proclamación respecto a los principios rectores que el Cap. III contempla, pero algunos de los preceptos contenidos en dicho Capítulo se refieren al ciudadano

38 Por ejemplo, art. 27.6: "Se reconoce a las personas fisicas y jurídicas la libertad de creación de centros docentes".

39 Nos referimos a la Declaración de los Derechos Humanos, 1948; Convenio sobre Eliminación de Discriminación Racial, 1965; Pacto Internacional de Derechos Civiles y Políticos, 1966; Pacto sobre Derechos Económicos, Sociales y Culturales, 1966; Convención sobre eliminación de discriminación contra la mujer, 1979. 
(arts. 41, 49 y 50). Precisamente, el artículo 49, referido a los discapacitados, habla del "disfrute de los derechos que este Titulo otorga a todos los ciudadanos". De este modo se evidencia la gran virtud de la Constitución de 1978 de recuperar y con tal fuerza el término ciudadano que se hallaba prácticamente perdido desde la Constitución gaditana, con la excepción del Proyecto de 1873 y las escasas alusiones hechas por la de 1931 .

El impulso dado por la Constitución a este ciudadano nuevo, esto es, a la idea actualizada de la ciudadanía, prendió como era lógico en los Estatutos de Autonomía, generando la figura del ciudadano autonómico, bien con la simple expresión ciudadano o su equivalente regional respectivo ("extremeños", "gallegos", etc). Los nuevos Estatutos aprobados desde 2006 intensifican muy notablemente este modo de señalar a los sujetos, siendo asimismo pujante la aparición en ellos de la palabra persona, siguiendo así la estela marcada por el Estatuto de Cataluña de 2006 en el que dicho término alcanza una presencia muy acusada. Como es bien sabido, largas listas de derechos públicos subjetivos y de principios rectores de la política social y económica a favor del ciudadano fueron insertadas en dichos Estatutos, abriendo con ello una polémica de altura sobre su pertinencia que luego abordaría el TC, como se dirá más adelante.

\section{C) El "ciudadano" en la legislación ordinaria}

La desaparición en las Constituciones decimonónicas de la referencia al "ciudadano" tiene su paralelo en las grandes leyes administrativas de finales del XIX y de casi todo el siglo XX, leyes que optan por otra terminología, señaladamente la de "interesado". Sin duda alguna puede afirmarse que en el plano de la legislación ordinaria la palabra interesado es y con gran diferencia, la "reina" de todos los vocablos. Y así resulta de la Ley de Procedimiento Administrativo de 1989 -Ley de Azcárateen la que no existe la menor alusión al ciudadano ni al administrado, siendo el "interesado" su protagonista casi exclusivo, lo cual, dicho sea de paso, es el término que le cuadra a una regulación referida a sujetos insertos en relaciones procedimentales $\operatorname{concretas}^{40}$. Lo dicho puede igualmente extenderse a las grandes leyes administrativas especiales de finales del XIX.

En la legislación de la postguerra civil el panorama se repite. En la Ley de Expropiación Forzosa de 1954 la invocación al "ciudadano" es inexistente, pese al hecho de que esta Ley también regula garantías, no sólo prerrogativas públicas; y ocurre exactamente lo mismo en la Ley de Régimen Local de 1955, aun tratándose de una norma tan cercana a los intereses de los ciudadanos ${ }^{41}$.

40 Lo mismo puede decirse del importante Reglamento de Procedimiento de las Reclamaciones económico administrativas, Real Decreto 15 de abril de 1890.

41 La legislación local tiene también sus protagonistas específicos: vecinos, residentes, transeúntes, domiciliados, cabezas de familia, habitantes, usuarios... y en los contados casos en los que la LRL 1955 
En cuanto a la legislación posterior, las escasas referencias a los ciudadanos durante toda la etapa preconstitucional inmediata comienzan a convivir con la voz "administrado" que va adquiriendo progresiva pujanza, siendo la primera vez en la historia que se produce esta convivencia. Por ello, la evolución de dichos conceptos será tratada seguidamente de manera conjunta en pro de la economía expositiva.

\section{LA FIGURA DEL ADMINISTRADO EN EL DEREGHO POSITIVO.}

\section{A) El "administrado" en la legislación preconstitucional.}

Ya ha quedado dicho que en las Leyes Fundamentales del franquismo no aparece el término "administrado". Por tanto, si se da pábulo a esa idea tan generalizada de que la voz "administrado" surge en el caldo de cultivo propio de un régimen dictatorial donde el sujeto hace de "súbdito", la ausencia del término en esas Leyes Fundamentales desmiente tal idea. Por ello, y en honor a la verdad, debe afirmarse que "administrado" no es una figura introducida por esa legislación para explicitar un estado de sumisión de las personas -ello haciendo abstracción de que las libertades fueran insuficientes o deficientemente garantizadas, que es otra cuestión-, sino que se trata de una aportación de la doctrina de los autores aceptada con toda naturalidad por la jurisprudencia, y viceversa.

Es cosa consabida la impregnación doctrinal que tuvo el Reglamento de Servicios de las Corporaciones Locales de $1955^{42}$; pues bien, persiste en este la ausencia de toda mención al ciudadano y en cambio ya asoman en él referencias al administrado ${ }^{43}$. Y en una Ley tan nuclear como la de Régimen Jurídico de la Administración del Estado de 1957 destacan la ausencia del ciudadano y una muy mínima presencia de la voz administrado.

La Ley de Procedimiento Administrativo de 1958, que tantos elogios ha recibido en todo tiempo ha sido acusada sin embargo de haber introducido, a través

necesita aludir al destinatario sin que estos sean esos sujetos específicos, utiliza el término "españoles", "personas", "particulares".

42 Es verdad consabida que el Reglamento de Servicios de las Corporaciones Locales de 1955, tan destacable por tantos conceptos, fue redactado bajo influencia doctrinal muy cualificada. Al corte dogmático de esta norme se refirió tempranamente CLAVERO ARÉVALO, M., en Revista de Administración Pública, núm. 19, 1956, págs. 287 y ss.

43 Incluso con un cierto aire paternalista ("...la Administración y sus administrados") arts. 1, 2, $4,5,8,10,11,31,34$. que no debe ser malinterpretado como indicativo de autoritarismo El uso de ese posesivo da pie a hacer interpretaciones negativas y muy equivocadas sobre lo que el Reglamento quiso decir; pues debe observarse, en primer lugar, que cuando dicha norma habla de "sus administrados" lo hace precisamente cuando consagra garantías para estos, no estados de sometimiento. Por otra parte, el posesivo "sus" lo que quiere indicar es que son "administrados" precisamente de la Administración local y no de otra; por tanto, su intención no es sojuzgar sino delimitar. 
de sus alusiones al "administrado", el estilo dictatorial propio del tiempo en el que nació. Pero esto no puede ser aceptado sin más, y hay razones muy sólidas para ello. En efecto, ha de tenerse en cuenta lo siguiente: $1^{\circ}$ ) la LPA prescinde de la noción de ciudadano porque al régimen político de la época le convenía alejarse de éste por sus resonancias liberales marchitas, incompatibles con el modelo de Estado social que el ideario oficial propugnaba ${ }^{44} ; 2^{\circ}$ ) en realidad, la voz administrado tiene en la Ley una presencia mínima $\mathrm{a}^{45} \mathrm{y}$ donde luce verdaderamente es en el Discurso de presentación de la Ley y en su Exposición de Motivos, lo que corrobora la procedencia puramente doctrinal de ese concepto, como ya ocurrió tres años antes con el Reglamento de Servicios de 1955, referido supra; $3^{\circ}$ ) la expresión administrado no es usada con esa intención peyorativa, tantas veces argüida por sus detractores, de hacer del ciudadano un "súbdito" dócil, sino precisamente todo lo contrario ${ }^{46}$; pues lo que postulan esos textos con la voz administrado era definir un tipo de ciudadano de nuevo cuño, colaborador y participativo ${ }^{47}$. Otra cosa es que la realidad del orden político y legal no ofreciera el marco general adecuado para el logro cabal de tal propósito; tan es así que, de hecho, lo regulado por la propia LPA fueron aspectos apegados al procedimiento administrativo; o sea, era una Ley para los interesados no para esa figura de "administrado" tan prometedora que anunciaban los discursos comentados.

44 En su presentación, a cargo de LÓPEZ RODÓ, L. Catedrático de Derecho Administrativo y a la sazón Ministro de la Presidencia, éste enfatizó la distancia que la nueva Ley venía a poner, en lo ideológico y en lo conceptual, respecto a la Administración del pasado, o sea, la que existía en tiempos de la Ley de Azcárate de 1889 con la que quería poner una visible barrera de separación, "un abismo" como llegó a decir expresamente. Y añadía: "El Estado liberal ha tenido que ceder el paso al Estado social de Derecho... de una actividad casi exclusivamente policial se ha pasado a una actividad de servicio público [...] Nadie quiere ahora una Administración inocua, sino idónea, rápida y eficaz [...] Esa Administración decimonónica montada para el "dejar hacer" no puede subsistir en un régimen político cuyo centro de gravedad es la actuación".

45 Tan sólo en cuatro ocasiones aparece la voz "administrado" - arts. 27, 37.2, 99.1 y 108.1- y no precisamente para definir un status o posición del particular ante al Estado. Son alusiones neutras, inocuas, sinónimas de "interesado".

46 La Exposición de Motivos - punto 6- reserva la palabra "administrado" para referirse al titular de un status con sus correspondientes derechos y deberes; por tanto un concepto más amplio y distinto del de interesado en un procedimiento concreto.

47 Así, el discurso dice que la colaboración de los administrados es una de las grandes metas que esta Ley se propone, añadiendo que "Como dice el profesor alemán Forsthoff, el Derecho administrativo ha pasado en los últimos tiempos, en el sentido de pasar de un sistema de limitaciones a un sistema de participación de los administrados". 
B) El administrado en la Constitución de 1978.

La mención de la Constitución al "administrado" es una singularidad mayúscula (art. 149.1.18 a $)^{48}$, algo sin precedente en toda nuestra historia constitucional ni en los textos constitucionales europeos; es más, tal figura no ha sido contemplada por ningún Estatuto de Autonomía lo que puede dar idea del rechazo que suscita desde que la democracia se implantó en España, al menos en este nivel normativo.

Pero se trata de un hecho palmario, por mucho rechazo que suscite en algunos; y por añadidura debe observarse que tal mención no figura en un precepto secundario sino en una norma central del sistema con un enorme poder de proyección sobre el ordenamiento jurídico. Y valga añadir este dato aunque sea de pasada: la fórmula pasó por todo el proceso constituyente sin discusión alguna ${ }^{49}$.

Por tanto, aunque sea a contracorriente vale afirmar que la constitucionalización del concepto administrado hay que valorarla como una aportación técnica de mucho interés por su notable virtud delimitadora de la que carece el concepto de ciudadano, si se retiene el dato de que el administrado no ha de ser necesariamente un ciudadano aunque en muchos casos lo sea. Siendo esto así y estando la Constitución fuera de toda sospecha de tratar a las personas como súbditos, nada hay que reprocharle al constituyente porque acogiera la figura del administrado en el lugar adecuado para ello - el entorno del procedimiento administrativo- con resolución y sin complejos ${ }^{50}$

Desde esta perspectiva el concepto de "administrado" suma más de lo que puede restar en el contexto político y jurídico de nuestros días. Lo creemos así: ante el lenguaje clarividente de la Constitución de 1978 han de sucumbir los seguidores del mero "lenguaje político correcto". Sacrificar el concepto de administrado como chivo expiatorio de los males del pasado es sencillamente un simplismo.

En consecuencia, la conclusión clara que se extrae de cuanto antecede es que la Constitución de 1978 no ha puesto en crisis ninguna de esas dos figuras; por el con-

48 El Estado tiene competencia exclusiva sobre las... "bases del régimen jurídico de las Administraciones públicas y del régimen estatutario de sus funcionarios que en todo caso garantizarán a los administrados un tratamiento común ante ellas"

49 Así lo hemos vuelto a resaltar en LÓPEZ MENUDO, F., "Significación de los conceptos de procedimiento común y de Régimen Jurídico. Razones y sinrazones de la reforma”, en Innovaciones en el Procedimiento Administrativo Común y el Régimen furídico del Sector Público, Dirig. F. López Menudo, Edit. Universidad de Sevilla, 2016, pág. 29.

50 Valga decir que si admitiéramos que las palabras son las responsables de los males que pudieran subyacer en ellas, expresiones como "Decreto ley", "sanción administrativa", "coacción directa", etc. tendrían que haber sido echadas a una imaginaria hoguera o a un museo de los horrores y sin embargo han supervivido y están en la Constitución. No cabe confundir los efectos con la causa. 
trario, a ambas las ha potenciado porque el constituyente tuvo la virtud de no enfrentarlas, o sea, de no secundar esa dialéctica que ha entretenido tanto a la doctrina. La convivencia en armonía de ambos conceptos resulta enriquecedora dado que no son antagónicos sino complementarios, sin que ninguno haya de perecer aunque sobre ellos pesen las cargas y la "mala fama" que el devenir histórico les ha ido echando encima, de las cuales, a estas alturas, están sobradamente purgados.

\section{V. "ADMINISTRADO" Y "CIUDADANO" EN LA LEGISLACIÓN ORDINARIA POSTERIOR A LA GONSTITUCIÓN.}

Aun así es de todo punto lógico que para ningún legislador resulte fácil ni cómodo optar por el uso de uno u otro término a la hora de referirse a las personas o de redactar una tabla de derechos o deberes; y en este forcejeo se desenvuelve la legislación postconstitucional, tanto sustantiva como procedimental.

Por lo que atañe a la figura del ciudadano su difusión ha sido muy intensa en el plano de la legislación ordinaria, estatal y autonómica, como es fácil de ver en las incontables tablas de derechos aparecidas a impulso de la Constitución y los Estatutos autonómicos que han sido referenciadas en estas páginas ${ }^{51}$. Y debe resaltarse que dicha legislación ha sido dictada no sólo en el campo de los derechos fundamentales clásicos donde el concepto de ciudadano cuadra como de molde, sino mayormente en el marco de la legislación social producida antes de la crisis económica iniciada en 2007, donde la expresión ciudadano ha demostrado esa su innata capacidad para encajar bien en escenarios diversos. Esas leyes, con sus listas interminables de derechos del más variado tipo ${ }^{52}$, erigen al "ciudadano" en pieza central del sistema, sin que al "administrado" se le dé el más mínimo juego, aunque en verdad luego sean los "administrados" - porque han de entenderse con la Administración- los destinatarios de esas normas y sus beneficiarios efectivos.

Un ejemplo muy representativo de esta especie de obsesión de los legisladores por explicitar su adhesión hacia la figura del ciudadano lo mostró la importante LRJAP y PAC ${ }^{53}$, dictada en desarrollo del artículo $149.1 .18^{a}$ CE catorce años después

51 Así como en la legislación local. El art. 69 de la LRBRL de 1985 se refiere a la participación de los ciudadanos, amén de otros preceptos concomitantes de la propia Ley.

52 Bien expresivo al respecto es el trabajo de FERNÁNDEZ RODRÍGUEZ, T.R. "¡Demasiados derechos!" en Derechos fundamentales y otros estudios en homenaje al Prof. Lorenzo Martín-Retortillo, Zaragoza, 2008, págs. 131 y ss. Una exposición de disposiciones autonómicas declaratorias de derechos en LÓPEZ MENUDO, F. "Los derechos sociales en los Estatutos de autonomía" en Actos del IV Congreso de la Asociación Española de Profesores de Derecho Administrativo, Lex Nova, Valladolid, 2009, págs.. 91 y ss.

53 Ley 30/ 1992 de Régimen Jurídico de las Administraciones Públicas y del Procedimiento Administrativo Común de 26 de noviembre de 1992. 
que ésta. La Exposición de Motivos y señaladamente su artículo 35 ("Derechos de los ciudadanos") muestran de modo elocuente la nueva actitud: exaltación del ciudadano y preterición del administrado. Este modo de dirigirse a los sujetos, mediante un término de tal abolengo, fue muy bien recibido por la doctrina ${ }^{54}$. Pero no puede obviarse el hecho de que un examen atento de los derechos contenidos en la tabla de dicho artículo 35 conectaba estos derechos, en su mayor parte, con los "interesados" (o los "administrados", por decirlo más ampliamente) pero no con los ciudadanos so riesgo de dar a este concepto un uso tan amplio que resultara incapaz de delimitar una porción siquiera de la realidad total generando así su disolución, convertido en un puro recurso gramatical sin contenido jurídico concreto.

Pese a todo, de esta fase posterior a la Constitución de 1978 es obligado resaltar un renacimiento colosal del término ciudadano con su séquito de derechos, atenciones nuevas y sus garantías a favor de los sujetos. Y paralelamente, una crítica a modo de cantinela contra la expresión administrado a la que se le siguen imputando tachas como si fueran imborrables, incluso bajo el techo constitucional existente desde 1978, tan incisivo en materia de derechos y libertades.

No cabe dudar de la influencia que esa literatura aparecida desde la Ley 30/1992 ha ejercido sobre las recientes Leyes 39 y 40/2015 $5^{55}$. Es notable la invocación al "ciudadano" que luce en ellas, si bien es cierto que el término en ellas dominante sea el de "personas". Y al propio tiempo hay que destacar el hecho de que en la primera de las leyes señaladas - la que según ella misma regula las relaciones " $a d$ extra" de la Administración- la presencia del "administrado" sea mínima, siendo nula en la segunda.

Ahora bien, es importante destacar el hecho significativo de que el artículo 13 de la Ley 39/2015, trasunto del artículo 35 de la LRJAP y PAC antes comentado, ya no se refiere globalmente a los ciudadanos, como este hacía, sino a los "Derechos de las personas" en sus relaciones con las Administraciones públicas ${ }^{56}$; lo que viene a ser una

54 Este precepto, según ELENA CÓRDOBA, A., es el que propicia nada menos que "la conversión de los habitantes de este país, desde su consideración como "administrados" en "ciudadanos" titulares de derechos y dotados de una posición activa de sus relaciones con la Administración...", por cuanto ofrece "un completo catálogo de derechos del ciudadano..." en el que cristaliza "el paso de administrado a ciudadano"; si bien el autor añade seguidamente matizaciones que relativizan la fuerza del precepto en cuestión y la de sus propias afirmaciones, "De administrado a ciudadano...", cit. pág. 559. Un estudio in extenso del citado art. 35 en EMBID IRUJO, A. "El ciudadano y...”, ob. cit. págs.. 53 y ss.

55 Leyes de 1 de octubre de 2015, del Procedimiento Administrativo Común de las Administraciones Públicas y de Régimen Jurídico del Sector Público, respectivamente (BOE 2 octubre 2015).

56 Esto sin perjuicio de los que figuran en el artículo 53, relativos a los derechos concretos ejercitables en un procedimiento por quienes tengan la condición de interesados; vid, GONZÁLEZ BUSTOS, M.A., "La actividad de las Administraciones Públicas" en La nueva Ley del Procedimiento Administrativo Común, dirig. H. GOSÁLBEZ PEQUEÑO, edit. WOLTERS KLUWER, Madrid, 2016, pág. 79 y ss. 
retractación, o sea, una prudente actitud por un uso más estricto y, por tanto, más técnico del término ciudadano. Una mejora esta que no ha sido objeto precisamente de elogio. Concretamente, algunos autores parten de considerar que esta Ley es regresiva en el campo de los derechos ciudadanos y que por ello - dicen- hubiese cuadrado mejor la expresión "administrado" por ser éste afín a la figura del súbdito ${ }^{57}$. Contra esta crítica conviene insistir en que el quid no está en el nomen de las cosas sino en lo que contienen y sus garantías.

\section{EL TRATAMIENTO DE DICHAS FIGURAS EN LOS TRIBUNALES.}

Con la obligada concisión - precisamente por su extensión gigantesca- cabe decir que una primera conclusión, muy esclarecedora, es que el número de Sentencias del Tribunal Constitucional que manejan el concepto de ciudadano es casi diez veces superior a las que utilizan la idea de administrado, diferencia que se nivela ostensiblemente en el ámbito de lo contencioso administrativo (Tribunal Supremo, Audiencia Nacional y Tribunales Superiores de Justicia). Pero al igual que ocurre en el ámbito de la legislación, en sede jurisdiccional la figura predominante con creces es la de interesado.

Aparte de este apunte puramente formal y global hay que añadir otras conclusiones de fondo. En primer lugar, ninguna sentencia del orden contencioso administrativo ha terciado de forma relevante en el debate sobre la dicotomía ciudadano-administrado, como sí ha hecho la doctrina científica. De otra parte, los tribunales sí abordan y con profusión el polémico tema de las relaciones de sujeción, manejando la consabida distinción entre administrados simples y cualificados, pero sin hacer cuestión de la existencia de la figura misma del "administrado" 58 . En suma, puede afirmarse que la jurisprudencia utiliza constantemente los conceptos de administrado y ciudadano como sinónimos ${ }^{59}$; la figura del "administrado no sólo no es repudiada, sino

57 Así lo estima CANO CAMPOS, T. en "Derechos y deberes de las personas en sus relaciones con las Administraciones Públicas: la vuelta del "administrado", en "Innovaciones del Procedimiento..., dirig. Cit., pág. 117, con cita en el mismo sentido de BAÑO LEÓN, J.M., "Súbditos de la Administración”, Tribuna del Diario EL PAIS del día 11 de mayo de 2016. Como se ve, el prejuicio negativo que levanta la figura del administrado es tal que incluso no desaparece ni siquiera en ocasión como esta en que la Ley no lo utiliza.

58 Muy significativa al respecto es la STC 185/1989 de 13 noviembre que incluso habla de la Administración y "sus administrados" como hiciera la normativa franquista citada supra. Son términos sinónimos también para la Sentencia STC 239/2007 de 10 de dicbre. (Delgado Barrio). Pero no faltan sentencias constitucionales que utilizan la figura del "administrado" de modo reiterado y concienzudo; así las 54/1982, 25/1983, 14/1986, 61/1997, 86/1998, 50/1999, 235/2000, 142/2009, 130/2013.

59 Así lo proclama expresamente la STS de 21 febrero 2011, Sala $5^{\text {a }: ~ “ . ~ . ~ . ~ a u n q u e ~ q u i z a ́ s ~ p o d i ́ a ~ h a-~}$ ber sido más correcto que el legislador hubiera empleado el término "ciudadano" en lugar de "administrado”, esta expresión es absolutamente sinónima, por cuanto que todos los residentes en un Estado, además de ciudadanos del mismo, son administrados de la misma manera que son sujetos de derechos y deberes y 
que es usada intensamente, incluso en algunos casos en los que hubiera cuadrado la palabra "ciudadano" o "interesado". O sea, que la "tormenta" que ha pasado y sigue pasando por la doctrina e incluso por las leyes, ha sido y es algo que no ha inquietado a los tribunales, lo que no es de lamentar.

\section{GONGLUSIÓN.}

La supervivencia histórica del concepto "ciudadano", pese a los borrones que le han venido acompañando como acabamos de ver, pone vivamente de manifiesto su indiscutible alcurnia histórica e ideológica y, por tanto, su enorme capacidad de resistencia ante cualquier movimiento que tendiera a su desplazamiento o descalificación. En la cultura occidental es indestructible e insustituible. Bien puede decirse de este concepto, parafraseando lo que el profesor GONZALEZ NAVARRO dice de la Constitución, que es una manera de entender el mundo, la vida y el hombre; y aparte de esto, todo lo que aporta por añadidura en el orden político y jurídico.

Después de lo que acaba de afirmarse ¿queda algún espacio para la figura del "administrado"? Ya ha quedado dicho, creemos que sí y que la Constitución de 1978 ha tenido el gran acierto de reconocerla contra viento y marea. Un tanto más que anotar en su favor.

Realzada ya suficientemente la significación del ciudadano nacido de la Constitución de 1978 y la mejora cualitativa y cuantitativa de sus derechos y garantías en esta etapa de nuestra historia, cabe preguntarse, tras tan enorme conquista, si ésta representa el summum de la perfección posible o si hay aspectos que mejorar y, en su caso, dónde haya que operar, si en el tejido de la propia Constitución, en el plano de la legalidad o en la pura mejora fáctica del funcionamiento de las instituciones.

Al hilo de lo que acaba de decirse, no cabe olvidar la concurrencia en esta última década de tres factores que han puesto en jaque a la figura del ciudadano, a sus legítimas expectativas e incluso a sus derechos subjetivos, quedando éstos literalmente arrasados en innumerables casos. Estos ataques han sido: a) la negación de que los derechos subjetivos proclamados directamente por las leyes constituyan verdaderos derechos ${ }^{60}$; b) los estragos derivados de la crisis económica con los consabidos

que son personas cuya dignidad ha de respetarse". Creemos que hay que quedarse con el pronunciamiento principal pues el subsiguiente no es del todo exacto. Otras muchas sentencias se mueven en esta sinonimia (p. ej. SSTS 16 marzo y 19 abril 2012; 30 junio, 29 sepbre. y 17 novbre. 2014; 24 marzo, 22 junio, 16 sepbre. y 5 octubre 2015, rec. núms. 1699/2010, 4488/2007; 520/2013, 1014/2013, 1634/2013; 757/2013, 3410/2013, 2247/2014 y 799/2014, respectivamente)

60 CÁMARA VILLAR, G. "Los derechos estatutarios no han sido tomados en serio (a propósito de la STC 247/2007 de 12 dicbre sobre el Estatuto de Autonomía de la Comunidad Valenciana" REDC, núm, 85, 2009. LÓPEZ MENUDO, F. "Los derechos sociales en los Estatutos...” cit. págs. 91 y ss. Poste- 
recortes, suspensiones o ceses de prestaciones sociales que los beneficiarios tenían reconocidas $^{61}$; c) la eclosión del fenómeno de la gestión privada de actividades y servicios públicos, otra novedad en la larga vida de la figura del ciudadano, esto es, la de tenerse que entender no ya con el Poder público - al cabo, "un adversario" no pocas veces "blando"- sino ante un poder de nuevo rostro, a veces invisible y, sin duda, menos sensible con la cosa pública: entidades privadas que buscan eficacia lucrativa y que de hecho lo suelen hacer muy alejadas de un teórico control administrativo.

Cierto es que son patologías que han afectado al ordenamiento jurídico entero y no exclusivamente al ciudadano - deben distinguirse siempre ambas esferas, aunque estén interrelacionadas- pero no cabe dudar que tales sucesos no han sido disfunciones "corrientes" del sistema legal sino fenómenos muy graves que por su propia índole han dado de lleno en la línea de flotación de la figura del ciudadano poniéndola en crisis.

Dicho sea en pocas palabras, tras un descalabro como el descrito no es de extrañar que el llamado "ciudadano de a pie" deje de creer en la fiabilidad de la Ley y la solidez de los derechos adquiridos, desconfíe de las instituciones e impute a la clase política - con la corrupción como argumento de refuerzo- casi todos los males; ingredientes todos ellos nada propicios para hacer resurgir esa "euforia participativa" de la que se hablaba hace tan pocos años. Actualmente, los ciudadanos más activos respecto a la cosa pública quizás no quieran tanto insertarse en el aparato público o participar en su gestión sino prescindir de éste e imponer sus propios criterios y decisiones, es decir, el logro de la llamada "democracia participativa", algo que la Constitución no permitió ${ }^{62}$, quizás desde una prudencia que hoy resulta comprensible a la vista del desarrollo de movimientos sociales señaladamente virulentos.

Dejando al margen la participación política de la que trata el artículo 23 CE, la participación en los restantes asuntos públicos es algo que aunque auspiciado por

riormente, sobre la STC 31/2010 que secundó la tesis de que no hay derechos subjetivos sin la interpositio legislatoris, nuestra crítica en Comentarios al Estatuto de Autonomía de Andalucía (dirig. Pedro CRUZ VILLALON y Manuel MEDINA GUERRERO), Parlamento de Andalucía, 2012, págs.. 189 y ss. PONCE SOLÉ, J, El derecho y la (ir) reversibilidad de los derechos sociales de los ciudadanos, INAP, Madrid, 2013.

61 EMBID IRUJO, A. "El Derecho Público de la crisis económica" en Actas del VI Congreso de la Asociación española de Profesores de Derecho Administrativo, INAP, 2012, págs. 21 y ss. EZQUERRA HUERVA, A. Crisis económica y Derecho Administrativo, Edit. Thomson Reuter Aranzadi, Pamplona, 2016. LÓPEZ MENUDO, F. "La situación de los servicios sociales en el actual escenario de crisis económica" en El marco jurídico de los servicios públicos en España, coord. Ezquerra Huerva, A, Edit. Atelier, Barcelona, 2012, págs. 29 y ss. PIÑAR MAÑAS, J.L. (coord.) Crisis económica y crisis del Estado del Bienestar, edit. Reus, Madrid, 2013.

62 Y que tiene clara traducción, por ejemplo, en el artículo 69.2. de la LRBRL al establecer que "Las formas, medios y procedimientos de participación que las Corporaciones establezcan en ejercicio de su potestad de autoorganización no podrán en ningún caso menoscabar las facultades de decisión que corresponden a los órganos representativos regulados por la Ley." 
la propia Constitución ${ }^{63}$ ha de desenvolverse en el marco de la democracia representativa que ésta consagra con la consiguiente supremacía de la Administración en la dirección, suspensión y control de las funciones y servicios públicos, lo que abre dos vías concretas a la participación $^{64}$, a las que hace referencia el art. 105 CE: la participación orgánica (incorporación a órganos administrativos) y la funcional (participación en procedimientos), una realidad multiforme pero cuyo denominador común es que el dominus y responsable de estas potestades es la Administración. De esta inmensa realidad debe distinguirse otra no menos gigantesca cual es el fenómeno de la colaboración y el ejercicio privado de funciones públicas que como bien ha señalado la doctrina no constituyen propiamente supuestos de participación en sentido técnico formal sino algo conceptualmente distinto con características propias y ajenas a la idea participativa.

Estas vías de participación no están exentas, desde luego, de problemas propios que el sistema ha ido generando (fenómenos de parasitismo en la participación orgánica; de abulia en la defensa de ciertos intereses y de espúreo activismo en otros, etc.) que han de sumarse a los quebrantos antes indicados y que deben tenerse muy en cuenta a la hora de valorar con realismo el estado de salud de la "ciudadanía" en el momento presente, lo que esta persiga a través de un posible cambio de modelo participativo y, en fin, ser muy consciente de lo que se hace antes de dar pasos hacia adelante en el caso de una eventual reforma de la Constitución en este punto.

63 Art. 9.2; 27.5; 129.1; 131

64 A ambas se refiere GARCÍA DE ENTERRÍA, E. "Sobre la participación ciudadana en la vida administrativa", Libro homenaje al Profesor fosé Luis VILLAR PALASÍ, Edit. Cívitas, Madrid, 1989, pág. 447. A ellas añade el autor la "participación cooperativa", esto es "colaborar de una manera voluntaria en programas o actividades que la Administración patrocina o promueve". Sobre el tema en general es obligado citar a SANCHEZ MORON, M., La participación del ciudadano en la Administración Pública, CEC, Madrid, 1980; y se ha de excusar la cita de muchos autores estudiosos del tema por simples razones de espacio. 